\title{
Maximum Diameter and Number of Tumors as a New Prognostic Indicator of Colorectal Liver Metastases
}

\author{
TOSHIAKI YOSHIMOTO, YUJI MORINE, SATORU IMURA, TETSUYA IKEMOTO, SYUICHI IWAHASHI, \\ YU SAITO, SINICHIRO YAMADA, DAICHI ISHIKAWA, HIROKI TERAOKU, \\ MASATO YOSHIKAWA, JUN HIGASHIJIMA, CHIE TAKASU and MITSUO SHIMADA \\ Department of Surgery, The University of Tokushima Graduate School, Tokushima, Japan
}

\begin{abstract}
Background: Surgical resection is currently considered the only potentially curative option as a treatment strategy of colorectal liver metastases (CRLM). However, the criteria for selection of resectable CRLM are not clear. The aim of this study was to confirm a new prognostic indicator of CRLM after hepatic resection. Patients and Methods: One hundred thirty nine patients who underwent initial surgical resection from 1994 to 2015 were investigated retrospectively. Prognostic factors of overall survival including the product of maximum diameter and number of metastases (MDN) were analyzed. Results: Primary tumor differentiation, vessel invasion, lymph node $(L N)$ metastasis, non-optimally resectable metastases, $H$ score, grade of liver metastases, resection with non-curative intent and MDN were found to be prognostic factors of overall survival (OS). In multivariate analyses of clinicopathological features associated with OS, MDN and non-curative intent were independent prognostic factors. Patients with $M D N \geq 30$ had shown significantly poorer prognosis than patients with MDN $<30$ in OS and relapse-free survival (RFS). Conclusion: $M D N \geq 30$ is an independent prognostic factor of survival in patients with CRLM and optimal surgical criterion of hepatectomy for CRLM.
\end{abstract}

The liver is the most common site of metastasis in patients with colorectal cancer (CRC) (1), with $15-25 \%$ of patients presenting synchronous colorectal liver metastases (CRLM) (2). In addition, another $25-50 \%$ of patients develop subsequent metachronous metastases during the course of the disease $(2,3)$. Surgical resection is currently considered the

This article is freely accessible online.

Correspondence to: Yuji Morine, MD, Department of Surgery, The University of Tokushima Graduate School, 3-18-15 Kuramoto-cho, Tokushima 770-8503, Japan. Tel: +81 88633 7139, Fax: +81 88 631 9698, e-mail: ymorine@tokushima-u.ac.jp

Key Words: Colorectal liver metastases, MDN, prognostic factor. only potentially curative option for patients with metastatic CRC confined to the liver $(4,5)$, and is associated with a 5year overall survival (OS) rate of $37-58 \%$ (6). However, only $15-30 \%$ of patients with liver metastases may be initially resectable $(7,8)$, but the criteria for selection of resectable CRLM remain unclear.

According to Nordlinger et al., patients with CRLM have been classified into three clinical categories: (i) patients with resectable metastatic disease; (ii) patients with metastatic disease that is not optimally resectable (tumor size $>5 \mathrm{~cm}$, $>4$ metastases, synchronous CRLM, primary lymph node (LN)-positive, positive tumor markers and/or technically difficult) and (iii) patients unlikely to ever become resectable (9). Neoadjuvant chemotherapy was recommended for patients with resectable and unresectable CRLM, whereas first-line surgical resection was recommended only for patients with solitary metastases $\leq 2 \mathrm{~cm}$ and good prognostic features (10). In the European Society for Medical Oncology (ESMO) consensus guidelines for the management of patients with CRLM, patients were categorized by technical and oncological criteria. Oncological categories include (i) concomitant extrahepatic disease; (ii) number of lesions $\geq 5$; (iii) tumor progression, with no mention of tumor size (11). However, clear criteria of surgical resection for CRLM have never been established.

On the other hand, in hepatocellular carcinoma, the Milan criteria are used for a simple selection for liver transplantation around the world. The adaptation of liver transplantation was limited to one lesion smaller than $5 \mathrm{~cm}$ or up to 3 lesions smaller than $3 \mathrm{~cm}$, and it is representing an approximate volume of tumor. In CRLM, simple criteria, using tumor number and size are required.

Perioperative or neoadjuvant chemotherapy with various agents, alone or in combination, is the standard of care for most patients with CRLM $(12,13)$. Neoadjuvant chemotherapy in patients with initially unresectable CRLM can reduce metastasis sizes, converting initially unresectable to resectable lesions (conversion treatment) (9), making systemic chemotherapy in combination with liver resection an accepted 
standard of care in patients with CRLM $(10,14)$. However, there are currently no particular criteria for resectability of CRLM, especially focusing on tumor volume in the liver.

The aim of this study was to confirm a new prognostic indicator of CRLM after hepatic resection.

\section{Patients and Methods}

Patients. This study was performed in accordance with the Helsinki Declaration of the World Medical Association. This retrospective study enrolled 246 patients with CRLM treated at Tokushima University Hospital from 1994 to 2015. Of these, 139 patients who underwent initial surgical resection with curative intent and without any preceding chemotherapy were included in this study. The remaining patients included 22 who received best supportive care and 85 who received systemic chemotherapy. Our treatment strategy for CRLM is curative hepatectomy whenever possible on all patients with CRLM if their remnant liver volume was $\geq 40 \%$, even after chemotherapy or hepatectomy.

Patients were evaluated preoperatively by abdominal ultrasound (US), helical computed tomography (CT) scan, and/or magnetic resonance imaging (MRI). All with CRC and synchronous or metachronous liver metastases were diagnosed histologically. Maximum tumor diameter and number of tumors were determined by CT and resected specimen. Resection status (curative vs. noncurative) was evaluated by histopathological assessment of excised metastases together with the operation notes.

The 139 patients included 85 men and 54 women with mean age $66 \pm 0.95$ years (range $=33-92$ years). The median patient follow-up for all patients was 48.7 months (range=4.4-162.1 months). Perioperative mortality was defined as death within 3 months of operation. In all 139 patients who underwent initial hepatic resection, the perioperative mortality was $0 \%$.

Methods. Staging and curability were defined according to the criteria of the Japanese Society for Cancer of the Colon and Rectum. Liver metastasis was classified as H1-3, with $\mathrm{H} 1$ defined as four or fewer tumors with a maximum diameter $<5 \mathrm{~cm}$; H3 as $>5$ tumors of size $>5 \mathrm{~cm}$; and $\mathrm{H} 2$ as anything intermediate. Liver metastasis grade was defined as $\mathrm{A}-\mathrm{C}$, with $\mathrm{H} 1$ and $\leq 3$ regional LN metastases classified as grade $\mathrm{A} ; \mathrm{H} 2$ with $\leq 3$ regional $\mathrm{LN}$ metastases or $\mathrm{H} 1$ with $\geq 4 \mathrm{LN}$ metastases classified as grade $\mathrm{B}$, and all other conditions classified as grade $\mathrm{C}$.

Statistical analysis. Univariate analysis of differences between groups was determined by log-rank tests and multivariate analysis by chi-squared tests. The endpoints were overall survival (OS) and relapse-free survival (RFS). Survival curves were plotted using the Kaplan-Meier method and 5-year OS and RFS rates were analyzed. Two-sided $p$-values $<0.05$ were considered statistically significant. All statistical analyses were performed using JMP version 13 statistical software (SAS, Campus Drive Cary, NC, USA).

\section{Results}

Overall and relapse-free survival. Survival curves of the 139 patients were plotted by the Kaplan-Meier method. The 5-year OS and RFS rates were $58.9 \%$ and $26.8 \%$, respectively (Figure 1). Median overall survival was 89.26 months $(\mathrm{SD}=2.92)$.

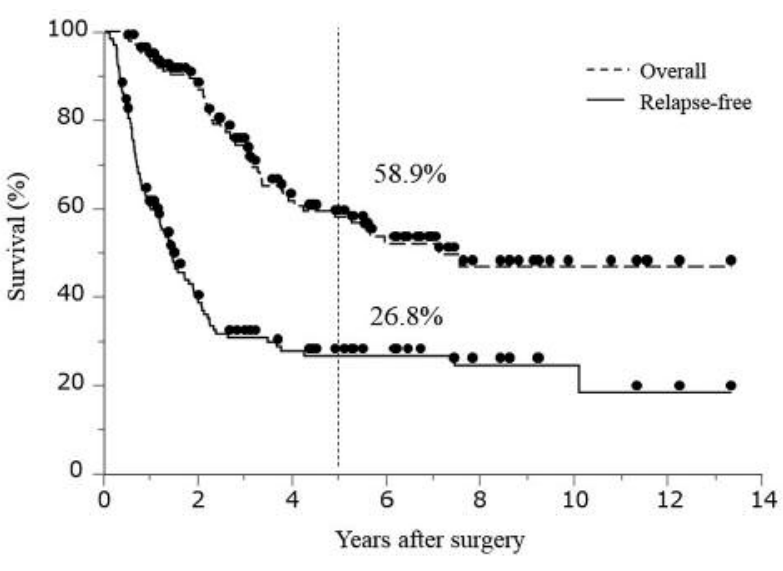

Figure 1. Overall and relapse-free survival curves of 139 patients with colorectal liver metastases who underwent initial surgical resection.

Univariate and multivariate analysis of clinicopathological features associated with overall survival. The product of maximum diameter and number (MDN) was newly defined as an indicator of tumor volume (or amount) in the liver. Table I shows univariate analyses of clinicopathological features associated with OS. Primary tumor differentiation $(p<0.0001)$, vessel invasion $(p=0.0458)$ and LN metastasis $(p=0.0089)$ were significantly prognostic of 5-year OS. Moreover, non-optimally resectable metastases $(p=0.0236)$, $\mathrm{H}$ score $(p=0.0265)$, grade of liver metastases $(p=0.0005)$, resection with non-curative intent $(p=0.0017)$, and MDN $(p=0.0006)$ were metastatic factors significantly prognostic for OS. Table II shows multivariate analyses of clinicopathological features associated with OS. MDN $(p=0.0145)$ and non-curative intent $(p=0.0451)$ were independently prognostic of survival in this patient cohort.

Relationships of MDN to OS and RFS rates. Figure 2a shows the Kaplan-Meier OS and RFS curves for these patients after initial hepatic resection. Patients with $\mathrm{MDN} \geq 30$ had significantly poorer prognosis than those with $\mathrm{MDN}<30$, with 5-year OS rates of $23.4 \%$ and $63.7 \%$, respectively $(p=0.0006 ;$ Figure 2a). MDN was also significantly prognostic of RFS, with patients with $\mathrm{MDN} \geq 30$ having significantly poorer prognosis than those with $\mathrm{MDN}<30$ $(p=0.018$; Figure 2b).

\section{Discussion}

CRLM may present synchronously in $15-25 \%$ of CRC patients, with an additional 30\% developing metastases during the course of the disease. Hepatic resection is the only potentially curative treatment for CRLM and may improve patient prognosis (15). Although approximately $20 \%$ of patients have potentially resectable metastases and a better 
Table I. Association between clinicopathological features and 5-year overall survival (OS) rates in patients who underwent surgical resection for colorectal liver metastases (CRLM).

\begin{tabular}{|c|c|c|c|}
\hline Factors & & 5 -year OS (\%) & $p$-Value \\
\hline Age & $\leq 65 />65$ & $56.0 / 62.2$ & 0.4691 \\
\hline Gender & $\mathrm{M} / \mathrm{F}$ & $64.3 / 50.5$ & 0.1543 \\
\hline Metastasis Period & Synchronous/metachronous & $50.2 / 68.1$ & 0.1081 \\
\hline CEA & $\leq 50 \mathrm{ng} / \mathrm{ml} />50 \mathrm{ng} / \mathrm{ml}$ & $58.8 / 65.0$ & 0.2362 \\
\hline CA19-9 & $\leq 100 \mathrm{U} / \mathrm{ml} />100 \mathrm{U} / \mathrm{ml}$ & $66.3 / 32.7$ & 0.0850 \\
\hline \multicolumn{4}{|l|}{ Primary site } \\
\hline Location & Colon/rectum & $63.5 / 52.5$ & 0.2427 \\
\hline Differentiation & tub/poor & $58.7 / 0$ & $<0.0001$ \\
\hline Lymphatic invasion & $-/+$ & $66.7 / 53.5$ & 0.6869 \\
\hline Vessel invasion & $-/+$ & $67.2 / 53.7$ & 0.0458 \\
\hline LN metastasis & $-/+$ & $72.7 / 48.9$ & 0.0089 \\
\hline \multicolumn{4}{|l|}{ Metastatic site } \\
\hline Non-optimally & $-/+$ & $78.7 / 48.6$ & 0.0236 \\
\hline $\mathrm{H}$ & $\mathrm{H} 1 / \mathrm{H} 2,3$ & $64.1 / 47.6$ & 0.0265 \\
\hline Grade & $\mathrm{A} / \mathrm{B}, \mathrm{C}$ & $72.9 / 42.5$ & 0.0005 \\
\hline Maximum diameter & $<5 \mathrm{~cm} />5 \mathrm{~cm}$ & $60.9 / 51.1$ & 0.2049 \\
\hline Number of tumors & $<5 />5$ & $62.6 / 46.0$ & 0.1380 \\
\hline MDN & $<30 />30$ & $62.9 / 23.4$ & 0.0006 \\
\hline Curative intent & Cur./non-Cur. & $60.5 / 0$ & 0.0017 \\
\hline Neoadjuvant & $-/+$ & $57.9 / 59.7$ & 0.5199 \\
\hline Adjuvant & $-/+$ & $61.2 / 57.9$ & 0.6285 \\
\hline
\end{tabular}

MDN: Maximum diameter $\times$ number.

chance of long-term survival (16), there is no definitive criteria for selection of resectable CRLM. Thus, defining resectable CRLM and developing treatment strategies are crucially important.

In Japan, there are five criteria for hepatectomy in patients with CRLM: (i) patient ability to tolerate surgery; (ii) primary tumor control or possibility of control; (iii) ability to completely resect the metastatic liver tumor; (iv) absence or possibility of control of extrahepatic metastases; and (v) adequate function of the remaining liver (17). CRLM treatment strategies in Japan do not limit tumor number or size.

Previous reports have shown that the number of tumors, largest tumor diameter, $\mathrm{LN}$ metastases of the primary tumor, CA19-9 concentration before hepatic resection and extrahepatic metastatic disease were predictive factors of survival after surgical resection of CRLM (15). These factors resulted in a nomogram prediction of disease-free survival following hepatic resection in patients with CRLM (18), but it was complicated in clinical use because of many risk factors.

Regarding to tumor number or size of CRLM, a previous report showed that the presence of $\geq 3$ tumors and tumor size $>8 \mathrm{~cm} \mathrm{(19)}$ and $>10 \mathrm{~cm} \mathrm{(20),} \mathrm{as} \mathrm{well} \mathrm{as} \geq 1$ tumor and tumor size $>5 \mathrm{~cm}$ (21), were negatively prognostic of OS. Other studies have reported that the presence of $\geq 3$ tumors and tumor size $>5 \mathrm{~cm} \mathrm{(22)} \mathrm{and} \mathrm{the} \mathrm{presence} \mathrm{of} \geq 4$ tumors and tumor size $>5 \mathrm{~cm}$ (23) were negatively prognostic. However,
Table II. Multivariate analysis of factors associated with 5-year overall survival (OS) rates in patients who underwent surgical resection of colorectal liver metastases (CRLM).

\begin{tabular}{llcc}
\hline Factors & & Odds ratio (95\% CI) & $p$-Value \\
\hline Primary site & & & \\
$\quad$ Differentiation & Poor & $6.428(0.833-134.207)$ & 0.0762 \\
Vessel invasion & + & $1.167(0.481-2.799)$ & 0.7291 \\
LN metastasis & + & $2.029(0.764-5.777)$ & 0.1578 \\
Metastatic site & & & \\
Non-optimally & + & $1.452(0.484-4.527)$ & 0.5074 \\
H & 2,3 & $1.590(0.397-6.591)$ & 0.5119 \\
Grade & B, C & $2.289(0.661-8.014)$ & 0.1886 \\
MDN & $>30$ & $6.503(1.432-37.232)$ & 0.0145 \\
Curative intent & non-Cur. & $4.082(1.818-9.174)$ & 0.0451 \\
\hline
\end{tabular}

MDN: Maximum diameter $\times$ number.

the significance of the dimensions of metastatic lesions as prognostic factors in CRLM surgery is controversial. Indeed, two independent studies found that the dimensions of metastases were not associated with local recurrence or 5year survival rates $(24,25)$. Thus, only the dimensions of metastases cannot be considered an exclusion criterion for surgery, unless they compromise the resection margins or the residual functional parenchyma (24). 

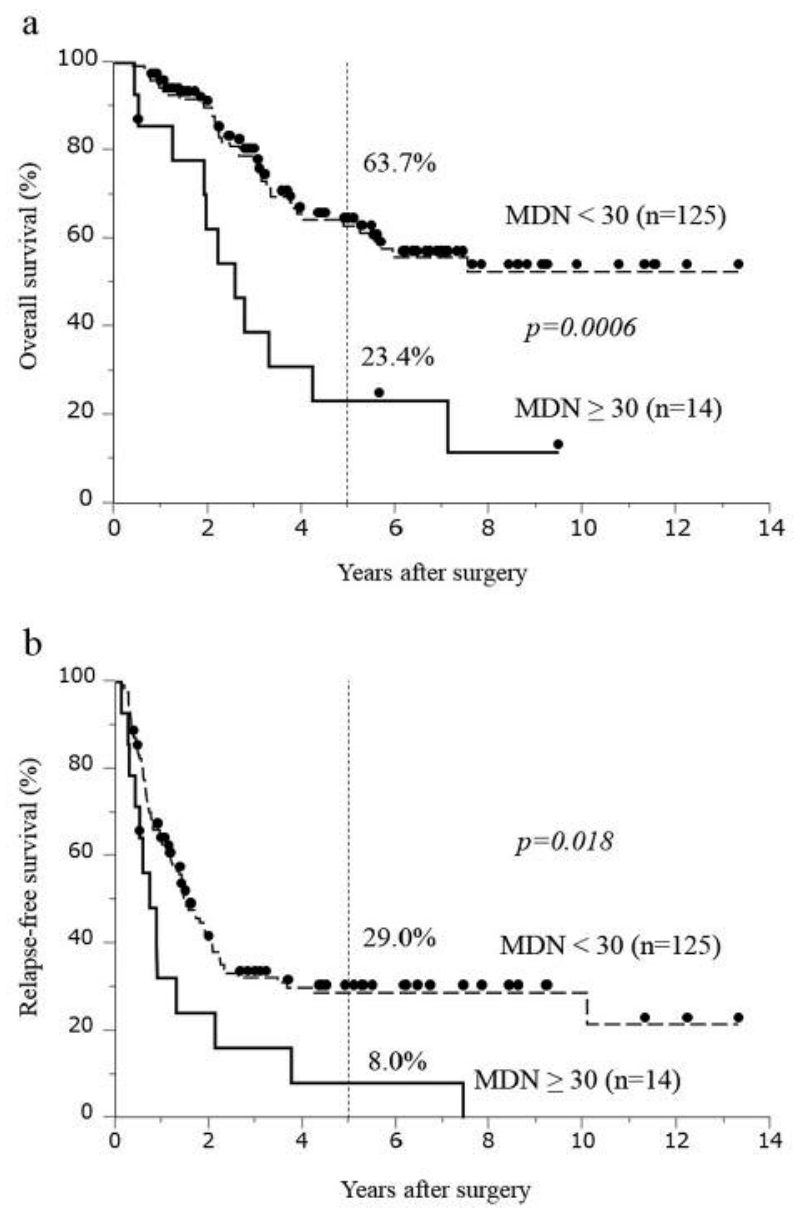

Figure 2. Kaplan-Meier curves for (a) overall survival and (b) relapsefree survival in patients with colorectal liver metastases (CRLM) of $M D N \geq 30$ and $<30$.

On the other hand, in the HCC, The Milan criteria limited the adaptation of liver transplantation to one lesion smaller than $5 \mathrm{~cm}$ or up to 3 lesions smaller than $3 \mathrm{~cm}$, and it is representing an approximate volume of tumor. Even in the CRLM, simple criteria for resectability especially focusing on tumor volume are required.

In regards to limit of hepatic resection, our institution is most aggressive in the world. In our department, curative hepatectomy was performed whenever possible on patients with CRLM, if the remnant liver volume was $\geq 40 \%$, even after chemotherapy or hepatectomy. In the criteria of the Japanese Society for Cancer of the Colon and Rectum, H3 liver metastasis was defined as $>5$ tumors and maximum diameter $>5 \mathrm{~cm}$. H3 liver metastasis was judged as not optimally resectable, but it corresponds to $\mathrm{MDN} \geq 25$. However, under the condition of aggressive hepatectomy, this study showed that MDN $\geq 30$ was the independent and strong prognostic factor of OS in patients with CRLM who underwent initial hepatectomy.

Based on these results, our department has devised a treatment strategy, in which patients with CRLM, MDN $<30$ and remnant liver volume $\geq 40 \%$ undergo hepatectomy, whereas those with $\mathrm{MDN} \geq 30$ and/or remnant liver volume $<40 \%$ receive chemotherapy. Patients regarded as nonoptimally resectable are treated with FOLFOXIRI plus Bevacizumab, with those showing a sufficient response undergoing subsequent liver resection.

In conclusion, this study showed that MDN was an independent prognostic factor of survival in patients with CRLM. MDN $<30$ is the optimal surgical criterion of hepatectomy for CRLM.

\section{References}

1 Gruenberger T, Bridgewater J, Chau I, García Alfonso P, Rivoire M, Mudan S, Lasserre S, Hermann F, Waterkamp D and Adam R: Bevacizumab plus mFOLFOX-6 or FOLFOXIRI in patients with initially unresectable liver metastases from colorectal cancer: the OLIVIA multinational randomised phase II trial. Ann Oncol 26(4): 702-708, 2015.

2 Lam VW, Pang T, Laurence JM, Johnston E, Hollands MJ, Pleass HC and Richardson AJ: A systematic review of repeat hepatectomy for recurrent colorectal liver metastases. J Gastrointest Surg 17(7): 1312-1321, 2013.

3 Lam VW, Laurence JM, Johnston E, Hollands MJ, Pleass HC and Richardson AJ: A systematic review of two-stage hepatectomy in patients with initially unresectable colorectal liver metastases. HPB 15(7): 483-491, 2013.

4 Umehara M, Umehara Y, Takahashi K, Murata A, Nishikawa S, Matsuzaka M, Tanaka $\mathrm{R}$ and Morita T: Preoperative Chemotherapy with Bevacizumab Extends Disease-free Survival After Resection of Liver Metastases from Colorectal Cancer. Anticancer research 36(4): 1949-1954, 2016.

5 Saied A, Katz SC and Espat NJ: Regional hepatic therapies: an important component in the management of colorectal cancer liver metastases. Hepatobiliary Surg Nutr 2(2): 97-107, 2013.

6 Liu W, Zhou JG, Sun Y, Zhang L and Xing BC: The role of neoadjuvant chemotherapy for resectable colorectal liver metastases: a systematic review and meta-analysis. Oncotarget 7(24): 37277-37287, 2016.

7 Veereman G, Robays J, Verleye L, Leroy R, Rolfo C, Van CE, Bielen D, Ceelen W, Danse E and De Man M: Pooled analysis of the surgical treatment for colorectal cancer liver metastases. Crit Rev Oncol Hematol 94(1): 122-135, 2015.

8 Sabanathan D, Eslick GD and Shannon J: Use of Neoadjuvant Chemotherapy Plus Molecular Targeted Therapy in Colorectal Liver Metastases: A Systematic Review and Meta-analysis. Clin Colorectal Cancer 15(4): 141-147, 2016.

9 Nordlinger B, Van CE, Rougier P, Köhne CH, Ychou M, Sobrero A, Adam R, Arvidsson D, Carrato A and Georgoulias V: Does chemotherapy prior to liver resection increase the potential for cure in patients with metastatic colorectal cancer? A report from the European Colorectal Metastases Treatment Group. Eur J Cancer 43(14): 2037-2045, 2007. 
10 Nordlinger B, Van CE, Gruenberger T, Glimelius B, Poston G, Rougier P, Sobrero A and Ychou M: Combination of surgery and chemotherapy and the role of targeted agents in the treatment of patients with colorectal liver metastases: recommendations from an expert panel. Ann Oncol 20(6): 985-992, 2009.

11 Schmoll HJ, Van Cutsem E, Stein A, Valentini V, Glimelius B, Haustermans K, Nordlinger B, van de Velde CJ, Balmana J, Regula J, Nagtegaal ID, Beets-Tan RG, Arnold D, Ciardiello F, Hoff P, Kerr D, Köhne CH, Labianca R, Price T, Scheithauer W, Sobrero A, Tabernero J, Aderka D, Barroso S, Bodoky G, Douillard JY, El Ghazaly H, Gallardo J, Garin A, Glynne-Jones R, Jordan K, Meshcheryakov A, Papamichail D, Pfeiffer P, Souglakos I, Turhal S and Cervantes A: ESMO Consensus Guidelines for management of patients with colon and rectal cancer. a personalized approach to clinical decision making. Ann Oncol 23(10): 2479-2516, 2012.

12 Brandi G, De Lorenzo S, Nannini M, Curti S, Ottone M, Dall'Olio FG, Barbera MA, Pantaleo MA and Biasco G: Adjuvant chemotherapy for resected colorectal cancer metastases: Literature review and meta-analysis. World J Gastroenterol 22(2): 519-533, 2016.

13 Pietrantonio F, Orlandi A, Inno A, Da Prat V, Spada D, Iaculli A, Di Bartolomeo M, Morosi C and De Braud F: Bevacizumabbased neoadjuvant chemotherapy for colorectal cancer liver metastases: Pitfalls and helpful tricks in a review for clinicians. Crit Rev Oncol Hematol 95(3): 272-281, 2015.

14 Khoo E, O'Neill S, Brown E, Wigmore SJ and Harrison EM: Systematic review of systemic adjuvant, neoadjuvant and perioperative chemotherapy for resectable colorectal-liver metastases. HPB 18(6): 485-493, 2016.

15 Jemal A, Bray F, Center MM, Ferlay J, Ward E and Forman D: Global cancer statistics. CA Cancer J Clin 61(2): 69-90, 2011.

16 Donadon M, Ribero D, Morris SG, Abdalla E and Vauthey N: New paradigm in the management of liver-only metastases from colorectal cancer. Gastrointest Cancer Res 1(1): 20-27, 2007.

17 Watanabe T, Itabashi M, Shimada Y, Tanaka S, Ito Y, Ajioka Y, Hamaguchi T, Igarashi $M$ and Ishida $H$ : Japanese Society for Cancer of the Colon and Rectum (JSCCR) Guidelines 2014 for treatment of colorectal cancer. Int J Clin Oncol 20(2): 207-239, 2015 .

18 Toru B, Yoshihiro S, Kiyoshi H, Goro H, Kuniya T, Yoshihito K, Hiroyuki N, Hiroyuki Y, Etsuro H, Masaki U, Hiroyuki T, Hideo B, Tomoo K, Norihiro K, Keiichi T, Itaru E, Go W, Masaru M, Shinji U, Tetsuo O, Ken K, Hiroki Y, Masakazu Y and Tadahiro $\mathrm{T}$ : A nomogram predicting disease-free survival in patients with colorectal liver metastases treated with hepatic resection: multicenter data collection as a Project Study for Hepatic Surgery of the Japanese Society of Hepato-Biliary-Pancreatic Surgery. J Hepatobiliary Pancreat Sci 19(1): 72-84, 2012.
19 Iwatsuki S, Dvorchik I, Madariaga JR, Marsh JW, Dodson F, Bonham AC, Geller DA, Gayowski TJ, Fung JJ and Starzl TE: Hepatic resection for metastatic colorectal adenocarcinoma: a proposal of a prognostic scoring system. J Am Coll Surg 189(3): 291-299, 1999.

20 Adam R, Delvart V, Pascal G, Valeanu A, Castaing D, Azoulay D, Giacchetti S, Paule B, Kunstlinger F and Ghémard O: Rescue surgery for unresectable colorectal liver metastases downstaged by chemotherapy: a model to predict long-term survival. Ann Surg 240(4): 644-658, 2004.

21 Fong Y, Fortner J, Sun RL, Brennan MF and Blumgart LH: Clinical score for predicting recurrence after hepatic resection for metastatic colorectal cancer: analysis of 1001 consecutive cases. Ann Surg 230(3): 309-318, 1999.

22 Pawlik TM, Scoggins CR, Zorzi D, Abdalla EK, Andres A, Eng C, Curley SA, Loyer EM, Muratore A and Mentha G: Effect of surgical margin status on survival and site of recurrence after hepatic resection for colorectal metastases. Anna Surg 241(5): 715-724, 2005.

23 Nordlinger B, Guiguet M, Vaillant JC, Balladur P, Boudjema K, Bachellier P and Jaeck D: Surgical resection of colorectal carcinoma metastases to the liver: a prognostic scoring system to improve case selection, based on 1568 patients. Cancer 77(7): 1254-1262, 1996.

24 Serrablo A, Paliogiannis P, Pulighe F, Moro SS, Borrego EV, Attene F, Scognamillo F and Hörndler C: Impact of novel histopathological factors on the outcomes of liver surgery for colorectal cancer metastases. Eur J Surg Oncol 42(9): 12681277, 2016.

25 Elias D, Cavalcanti A, Sabourin JC, Pignon JP, Ducreux M and Lasser P: Results of 136 curative hepatectomies with a safety margin of less than $10 \mathrm{~mm}$ for colorectal metastases. J Surg Oncol 69(2): 88-93, 1998.
Received March 3, 2017

Revised March 20, 2017

Accepted March 22, 2017 